Anaesthesist 2017 66 :373-374

DOI 10.1007/s00101-017-0303-7

Online publiziert: 29. März 2017

(c) Springer Medizin Verlag GmbH 2017

CrossMark

\section{U. Jaschinski}

Klinik für Anästhesiologie und Operative Intensivtherapie, Klinikum Augsburg, Lehrkrankenhaus LMU

München, Augsburg, Deutschland

\section{Erratum zu: Intensivtherapie nach aneurysmatischer Subarachnoidalblutung}

Erratum zu:

Anaesthesist 2016 65: 951-970

DOI 10.1007/s00101-016-0242-8

Der Autor macht auf einen Fehler aufmerksam. AufS. 965 in dem Abschn. „Gestörte Hypophysenfunktion“ steht: In der Akutphase dominiert die Dysfunktion des Hypophysenvorderlappens.

Es muss jedoch heißen: Hypophysenhinterlappen (HHL).

\section{Korrespondenzadresse}

\section{Dr. med. U. Jaschinski}

Klinik für Anästhesiologie und Operative Intensivtherapie, Klinikum Augsburg,

Lehrkrankenhaus LMU München

Stenglinstrasse 2, 86156 Augsburg,

Deutschland

ulrich.jaschinski@klinikum-augsburg.de 
Hier steht eine Anzeige.

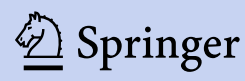

